\title{
Изменение функциональных параметров листьев видов р. Betula вдоль градиента аридности климата в Южной Сибири и Монголии
}

\section{Changes in leaf functional parameters of species from genus Betula along the gradient of climate aridity in Southern Siberia and Mongolia}

\author{
Мигалина С. В., ${ }^{1,2}$ Иванов Л. А. ${ }^{1,2}$, Иванова Л. А., ${ }^{1,2}$ \\ Migalina S. V. ${ }^{1,2}$, Ivanov L. A. ${ }^{1,2}$, Ivanova L. A. ${ }^{1,2}$ \\ ${ }^{1}$ Ботанический сад Уральского отделения РАН, г. Екатеринбург, Россия. E-mail: Fterry@mail.ru \\ ${ }^{2}$ Тюменский государственный университет, г. Тюмень, Россия \\ ${ }^{1}$ Institute Botanical garden, Ural branch, Russian Academy of Sciences, Ekaterinburg, Russia \\ ${ }^{2}$ Tyumen State University, Tyumen, Russia
}

\begin{abstract}
Peфepam. Исследовали параметры листьев в популяциях Betula pendula Roth из Южного Зауралья и Betula platyphylla Sukacz. из Южной Сибири и Монголии. Показано, что с усилением аридности климата увеличиваются толщина и плотность листа, что указывает на структурные и функциональные изменения листового аппарата в условиях водного дефицита. Данные параметры можно считать маркерными признаками, отражающими адаптацию фотосинтетического аппарата берез к изменению климатических условий.
\end{abstract}

Ключевые слова. Адаптация, аридность климата, лист, функциональные параметры, Betula.

Summary. Leaf parameters were studied in populations of Betula pendula Roth and Betula platyphylla Sukacz. from southern Urals, Southern Siberia and Mongolia. It was shown that leaf thickness and density increase under increasing of climate aridity, that indicates structural and functional changes in leaves of birch trees under conditions of water deficit. These parameters can be considered as indicators of photosynthetic apparatus adaptation of birch trees to climate changes.

Key words. Adaptation, Betula, climate aridity, functional parameters, leaf.

Адаптация растений основана на регуляции фотосинтеза, которая обеспечивается изменением структуры фотосинтетического аппарата на разных уровнях его организации (Мокроносов,1978; Иванова и др., 2006). Эффективным методом определения механизмов адаптации фотосинтетического аппарата растений к воздействию климата является изучение листовых параметров вдоль климатических градиентов (Мигалина и др., 2014). Толщина и удельная поверхностная плотность листа (УППЛ) считаются наиболее важными листовыми признаками, характеризующими жизненную стратегию растений (Westoby, 1998; Niinemets, 1999), поскольку они тесно связаны с относительной скоростью роста (Poorter, Remkers, 1990) уровнем нетто-фотосинтеза (Ellsworth, Reich, 1992), содержанием азота в листьях (Wright et al., 2004) и продолжительностью жизни листьев (Shipley, Vu, 2002). Целью данной работы было определить характер изменения функциональных параметров листа берез вдоль градиента аридности климата.

Исследования проводили в популяциях Betula pendula Roth в Южном Зауралье и близкого ей вида Betula platyphylla Sukacz. в Южной Сибири и Монголии (табл.). Данные виды являются викарирующими и произрастают в сходных экологических условиях. Для анализа листовых параметров в каждой популяции с 10 деревьев отбирали полностью сформированные листья в нижней трети кроны южной экспозиции. Определяли площадь, толщину и удельную поверхностную плотность листа. Площадь листа определяли с использованием уникального комплекса для анализа изображений Simagis Mesoplant (СИАМС, Россия). Толщину листа измеряли электронным цифровым микрометром PK1012E (Mitutoyo, Япония). Удельную поверхностную плотность листа определяли взвешиванием листьев, предварительно высушенных при $\mathrm{t}=75^{\circ} \mathrm{C}$. 
Местоположение районов исследования

\begin{tabular}{|c|c|}
\hline Местоположение & $\begin{array}{c}\text { Координаты (с.ш., в.д.), } \\
\text { высота над ур. м. }\end{array}$ \\
\hline Южный Урал, Челябинская область, п. Бреды & $\begin{array}{c}\mathrm{N}=52^{\circ} 25^{\prime}, \mathrm{E}=60^{\circ} 21^{\prime} \\
\mathrm{H}=302 \mathrm{M}\end{array}$ \\
\hline Южный Урал, Челябинская область, г. Троицк & $\begin{array}{c}\mathrm{N}=54^{\circ} 06^{\prime}, \mathrm{E}=61^{\circ} 35^{\prime} \\
\mathrm{H}=177 \mathrm{M}\end{array}$ \\
\hline Бурятия, пос. Курумкан & $\begin{array}{c}\mathrm{N}=54^{\circ} 24^{\prime}, \mathrm{E}=110^{\circ} 23^{\prime}, \\
\mathrm{H}=513 \mathrm{M}\end{array}$ \\
\hline Бурятия, пос. Ина & $\begin{array}{c}\mathrm{N}=53^{\circ} 77^{\prime}, \mathrm{E}=110^{\circ} 26^{\prime} \\
\mathrm{H}=756 \mathrm{M}\end{array}$ \\
\hline Бурятия, пос. Турунтаево & $\begin{array}{c}\mathrm{N}=52^{\circ} 10^{\prime}, \mathrm{E}=107^{\circ} 42^{\prime} \\
\mathrm{H}=550 \mathrm{M}\end{array}$ \\
\hline Монголия, сом. Шамар & $\begin{array}{c}\mathrm{N}=49^{\circ} 55^{\prime}, \mathrm{E}=106^{\circ} 00^{\prime} \\
\mathrm{H}=899 \mathrm{M}\end{array}$ \\
\hline Монголия, окрестности сом. Сумбэр, & $\begin{array}{c}\mathrm{N}=49^{\circ} 09^{\prime}, \mathrm{E}=106^{\circ} 02^{\prime} \\
\mathrm{H}=934 \mathrm{M}\end{array}$ \\
\hline Монголия, сом. Баянчандмань & $\begin{array}{c}\mathrm{N}=48^{\circ} 07^{\prime}, \mathrm{E}=106^{\circ} 25^{\prime} \\
\mathrm{H}=1530 \mathrm{M}\end{array}$ \\
\hline
\end{tabular}

Полученные результаты показали, что площадь листа не имела закономерных изменений в зависимости от степени засушливости климата (рис.). Уральские популяции берез отличались меньшими размерами листовой пластинки по сравнению с березами Западного Забайкалья. Толщина листа увеличивалась вдоль градиента широтного градиента, достигая максимальных значений в южной части трансекты (рис.). Нами также отмечено увеличение УППЛ в популяциях берез с уменьшением географической широты и увеличением засушливости климата (рис.). Утолщение и уплотнение листовой пластинки является одним из механизмов адаптации берез к аридности климата, поскольку такие структурные перестройки листовой пластинки в условиях повышенной сухости воздуха защищает лист от излишних транспирационных потерь. Кроме того, увеличение плотности листьев может быть связано с развитием внутрилистовой ассимиляционной поверхности мезофилла, что способствует снижению мезофильного сопротивления для $\mathrm{CO}_{2}$ (Niinemets, 2001; Иванова и др., 2006; Terashima et al, 2011). Ранее для большого количества видов травянистых растений было показано увеличение УППЛ вдоль градиента аридности климата в степных и пустынных сообществах Северной Евразии (Иванов и др., 2008, 2009). В этой связи увеличение плотности листа у берез вдоль изученного широтного градиента можно рассматривать в качестве одного из направлений адаптации фотосинтетических органов древесных растений к аридности климата.

Таким образом, полученные результаты показали, что с усилением аридности у исследованных видов берез увеличиваются толщина и плотность листа, что свидетельствует о структурно-функциональных перестройках листового аппарата берез, которые направлены на снижение транспирационных потерь и увеличение скорости внутрилистовой диффузии $\mathrm{CO}_{2}$ в условиях водного дефицита. Толщина и плотность листа могут считаться маркерными признаками, отражающими адаптацию фотосинтетического аппарата берез к увеличению аридности климата.

Работа выполнена в рамках государственного задания Ботанического сада УрО РАН, а также при финансовой поддержке РФФИ 17-29-05019. 

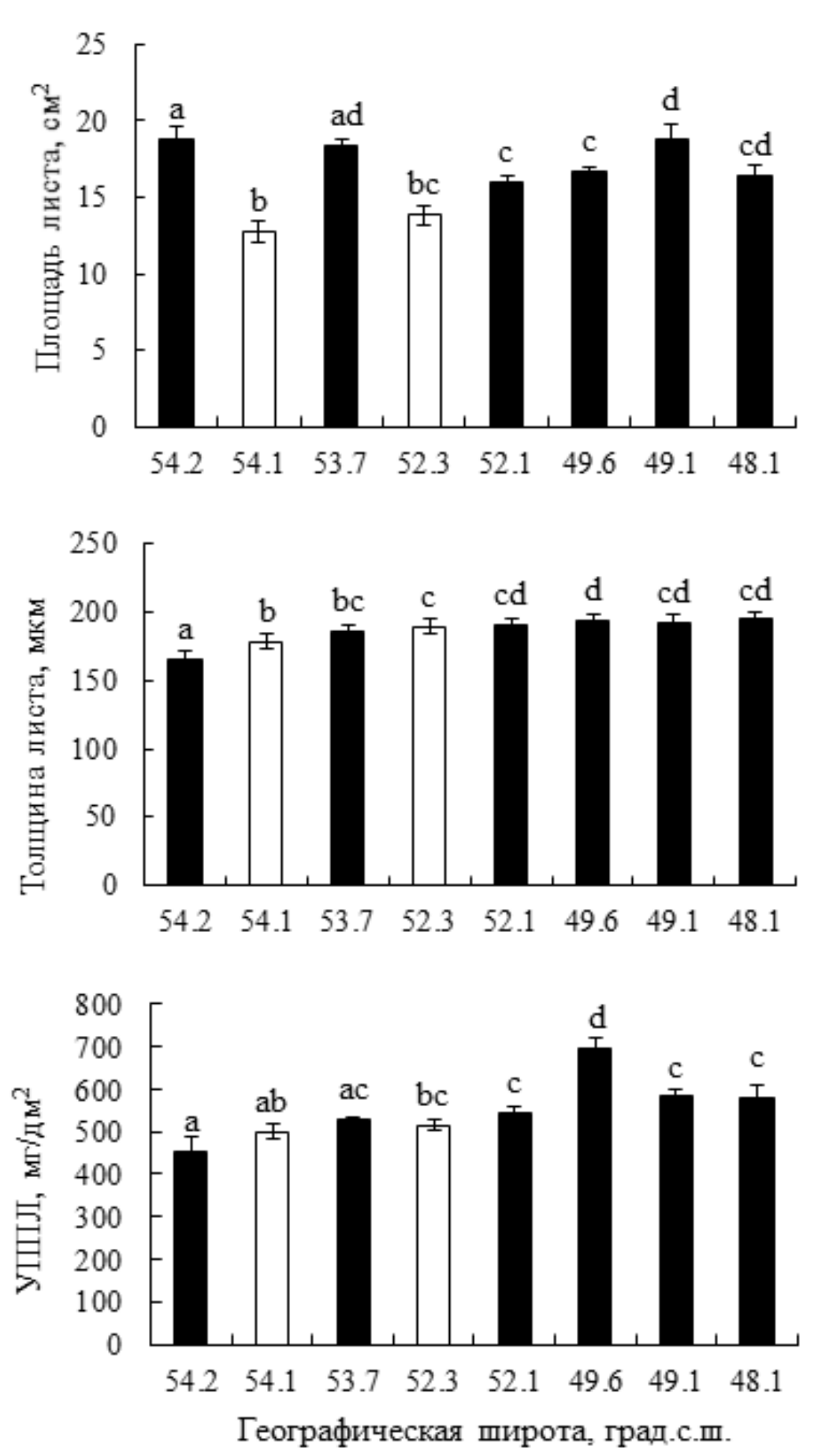

Рис. Изменение параметров листа берез вдоль градиента аридности климата. УППЛ - удельная поверхностная плотность листа. $\square$ - Южное Зауралье, Betula pendula; - Бурятия, Монголия, Betula platyphylla.

\section{ЛИТЕРАТУРА}

Иванова Л. А., Петров М. С., Кадушников Р. М. Определение диффузионного сопротивления мезофилла Chamaerion angustifolium методом трехмерной реконструкции клеточной упаковки листа // Физиология растений, 2006. - Т. 53, №3. - С. 354-363.

Иванов Л. А., Ронжина Д. А., Иванова Л. А. Изменение листовых параметров как показатель смены функциональных типов степных растений вдоль градиента аридности // Физиология растений, 2008. - Т. 55. - С. $332-339$.

Иванов Л. А., Иванова Л. А., Ронжина Д. А. Закономерности изменения удельной плотности листьев у растений Евразии вдоль градиента аридности // Доклады Академии Наук, 2009. - Т. 428, №1 - С. $135-138$. 
Мигалина С. В., Иванова Л. А., Махнев А. К. Генетическая детерминированность объема клетки мезофилла листа берез как адаптация фотосинтетического аппарата к климату // Доклады Академии Наук, 2014. - Т.459, № 6. - С. 765-768.

Мокроносов $\boldsymbol{A}$. T. Мезоструктура и функциональная активность фотосинтетического аппарата. -

Свердловск: Изд-во Урал. гос. ун-та, 1978. - 147 с.

Ellsworth D. S., Reich P. B. Leaf mass per area, nitrogen content and photosynthetic carbon gain in Acer saccharum seedlings in contrasting forest light environments // Functional Ecology, 1992. - Vol. 6. - P. 423-435.

Niinemets $\ddot{U}$. Components of leaf dry mass per area - thickness and density - alter leaf photosynthetic capacity in reverse directions in woody plants // New Phytologist, 1999. - Vol. 144. - P. 35-47.

Niinemets $\boldsymbol{U}$. Global-scale climatic controls of leaf dry mass per area, density, and thickness in trees and shrubs // Ecology, 2001. - Vol. 82, № 2. - P. 453-469.

Poorter H, Remkes $\boldsymbol{C}$. Leaf area ratio and net assimilation rate of 24 wild species differing in relative growth rate // Oecologia, 1990. - Vol. 83. - P. 553-559.

Pyankov V.I., Ivanova L.A., Lambers H. Quantitative anatomy of photosynthetic tissues of plant species of different functional types in boreal vegetation // Inherent variation in plant growth. Physiological mechanisms and ecological consequences / Eds. H. Lambers, H. Poorter, M.M.I. Vuuren. Leiden: Backhuys, - 1998. - P. 71-87.

Shipley B., $V \boldsymbol{u}$ T. Dry matter content as a measure of dry matter concentration in plants and their parts // New Phytologist, 2002. - Vol. 153. - P. 359-364.

Terashima I, Hanba YT, Tholen D, Niinemets $U$. Leaf functional anatomy in relation to photosynthesis. // Plant Physiology, 2011. - Vol. 155. - P. 108-116.

Westoby M. A leaf-height-seed (LHS) plant ecology strategy scheme // Plant and Soil, 1998. - Vol. 199. - P. $213-227$.

Wright I. J., Reich P. B., Westoby M., Villar R. The worldwide leaf economics spectrum // Nature, 2004. - Vol. 428. - P. 821-827. 